\title{
Effect of Self Learning Package Based on Health Belief Model on Cervical Cancer Prevention among Female University Students
}

\author{
Hanaa, A.A. Yossif ${ }^{1} \&$ Hend, A. EL Sayed ${ }^{2}$ \\ ${ }^{I}$ Assistant Professor of Community Health Nursing, Faculty of Nursing, Benha University, Egypt \\ ${ }^{2}$ Lecturer of Obstetrics and Woman Health Nursing, Faculty of Nursing, Benha University, Egypt \\ E-mail: ${ }^{1}$ hana.youssef@ fnur.bu.edu.eg ${ }^{2}$ hend.afify@fnur.bu.edu.eg
}

\begin{abstract}
:
Aim: of this study was to estimate the effect of self-learning package based on health belief model on cervical cancer prevention among female university students.
\end{abstract}

Design: Quasi- experimental design was utilized.

Sample: A purposive sample of 314 married female students out of ( $n=1463)$ and randomly divided into an intervention group (157) and control group (157).

Setting: The study was carried out at 13 Faculties in Benha University.

Tools: Data were collected through three main tools: A self-administered questionnaire to assess students' general characteristics and knowledge regarding cervical cancer prevention, health belief model, and questionnaire to assess intention to practice cervical cancer prevention behaviors.

Results: There was improvement with highly statistically significant difference observed in intervention group regarding knowledge items about cervical cancer prevention after self-learning package implementation. The mean scores of perceived susceptibility and severity of cervical cancer, as well as perceived benefits of early detection and HPV vaccination were significantly higher in the intervention group compared to control group. More than one third and more than half of the intervention group respectively compared with few of the control group have intent to take HPV vaccination and do Pap smear respectively.

Conclusion: The self-learning package based on health belief model enhances student's knowledge, change positively health beliefs and intention regarding cervical cancer prevention.

Recommendation: Dissemination of cervical self learning package based on HBM among female university students to prevent the risk of cervical cancer.

Key Words: Cervical Cancer Prevention, Health Beliefs Model, Self Learning Package

\section{Introduction}

Cervical cancer is a major worldwide health problem. Nearly 250,000 women die from the disease each year and about $80 \%$ of the cervical cancer deaths occurring in developing countries. It is the foremost cancer killer of female in the developing countries and is the second most common malignancy in female worldwide after breast cancer, in the third world cervical cancer is the common cancer, where over $75 \%$ newly diagnosed from half a million cases occur annually [1]. This high incidence is attributed to paucity of and inadequacy of screening programs as well as the unawareness of the disease in less developed countries. Cancer of the cervix is a crucial of females' reproductive problem specifically in the developing countries [2].

The primary underlying cause for cervical cancer is human Papillomavirus (HPV). Infections with HPV are most commonly seen in young, sexually active females, with the highest prevalence in females under 25 years. Commonly females are infected with human papillomavirus at age of 20 years, but cervical cancer sign and symptoms cannot appear up to twenty years [3]. The other known risk factors for cervical cancer are the early sexual activities, multiple sex partners, prolonged utilization of oral contraceptives, immunosuppressive disease, sexually transmitted infection, smoking and particularly dietary factors [4].

Cervical cancer disease can be prevented, if it is early detected by a extended, pre-invasive treatment stage that can be started with routine cervical screening, of which the Pap smear remains the primary tool [5].Currently, vaccine against HPV has been found to be the most effective known method in preventing cervical cancer among women who have not previously been exposed to HPV [6]. However, several studies have found that early detection are disturbed by poor knowledge, wrong behaviors and beliefs related to cervical cancer screening in women which may have important impact on the women decision to practice preventive measures against cancer of the cervix $[7,8,9]$. 
Furthermore, self learning method is an individualized method of learning. Face to face teaching is disappearing and distance mode of education is becoming popular. Self learning package (SLP) are developed to allow the learner to be free to select what, how, when and where to learn. This flexibility is an importance characteristic in open learning process. The learner becomes accustomed more and more to non-formal mode of education thereby shifting the preference to self learning methods [10].

The Health Belief Model (HBM) was designed to illustrate preventive health behaviors instead of behaviors during illness. The most important health behaviors highlighted by the HBM emphasize on prevention or exposure of diseases at their asymptomatic stage. HBM has been broadly applied to several health behaviors, specifically screening behaviors [11]. HBM adopts that health behaviors are determined by four items; perceived susceptibility, severity, barriers, and benefits [12].

Nurses play a vital role in cervical cancer prevention as they are important individual in health care system [13]. Nurses generally play a major role in health education and promotion. Moreover, nurses who well trained perform well in cervical cancer screening and cervical precancerous sores treatment [14]. Also nurses have an vital task of conveying information on risk factors, detection of early signs of cervical cancer and motivate females to perform cervical cancer screening regularly [15].

\section{Significance of the study:}

Egypt has a population of 28.37millions females ages 15 years and older who are at risk of developing cervical cancer. The recent estimations show that 866 women are determined to have cervical cancer annually and about 373 women loss their lives from the disease. Cervical cancer ranks as the $13^{\text {th }}$ most frequent cancer among females in Egypt and the 10th most frequent cancer among females between 15 and 44 years of age [16].

A health education methods as self learning package that presents information about cervical cancer prevention may be the key to changes in cervical cancer knowledge and beliefs as well as preventive behaviors. Moreover, the HBM is one of the models that commonly used as a guiding frame for health behavior interventions, especially cervical screening behavior [17]. Therefore, this research was planned to estimate the effects of self learning package based on HBM on knowledge, health beliefs and intent to practice preventive health behaviors of cervical cancer.

\section{Aim of the study:}

The aim of this study was to estimate the effect of self-learning package based on health belief model on cervical cancer prevention among female university students. This aim achieved through:

- Measuring the female university student's knowledge, and health beliefs about prevention of cervical cancer as well as their intention to practice cervical cancer prevention behaviors to identify their needs.

- Designing and implementing self learning package based on health belief model according to female university student's needs.

- Evaluating self learning package effect on female university student's knowledge, health beliefs, and intention regarding cervical cancer prevention.

\section{Hypothesis:}

The female university students who received self learning package based on health belief model would predicted to improve their knowledge regarding cervical cancer prevention, positive changes of health beliefs about cervical cancer prevention, and the intent to perform cervical cancer prevention behaviors as revealed by pre and post tests scores compared with the control group.

\section{Subjects And Methods}

Research design: Quasi- experimental design was utilized to fulfill the aim of this study

\section{Setting:}

The study was carried out at 13 Faculties in Benha University, including both scientific and literary faculties except Faculty of Physical Education for males. The study included Faculties of (Arts, Law, Commerce, Science, Medicine, Engineering, Agriculture, Computing and Information, Higher Institute of Technology, Veterinary Medicine, Education, Specific Education and Nursing).

\section{Sample:}

A purposive sample of 314 female students out of $(n=1463)$ married female students from both scientific and literary faculties were included in the current study according to inclusion criteria: Female students who registered in third and fourth academic years, married, and agreed to participate in the research. The sample was randomly divided into an intervention group (157) and control group (157). Sample size was 
calculated according to the following equation [18].

$$
n=\frac{N}{1+N(e)^{2}}
$$

\section{Tools of data collection:}

Three tools were used for data collection.

First tool: A structured self-administered questionnaires that were designed by the researchers in simple Arabic language after revising of related literature [19, 20]. It comprised three main parts:

Part I: Student's socio -demographic characteristics, such as age, type of Faculty, academic year, monthly income and family history.

Part II: Marital and obstetric history, which include: age at marriage, duration of marriage, parity, and use of contraceptive methods and its kinds.

Part III: Knowledge of the studied students regarding cervical cancer and its prevention. This part was utilized before and after self learning package implementation (pre/posttest format), it included twenty one multiple choice questions which divided into three portions.

1- To measure students' knowledge regarding the cervical cancer, it included (seven) questions (meaning, causes, risk factors, symptoms, diagnosis, methods of treatment, methods of prevention).

2- To measure students' knowledge regarding the cervical cancer screening which comprised of (nine) questions as (meaning of Pap smear screening, who need Pap smear screening, purpose, part of body which Pap test checked, time of beginning cervical cancer screening, frequency of Pap smear/year, preparations needed before screening, what meant by abnormal Pap test, and follow up after abnormal Pap test).

3- To measure cervical cancer vaccination knowledge which consisted of (five) questions as (availability of vaccine, target population for vaccine, recommended age group for taking vaccine, vaccine dose and safety of vaccine).

\section{Scoring system of knowledge:}

A correct answer was scored "one" and the incorrect "zero". The knowledge score was calculated by adding the scores for the correct answers. The total knowledge score ranged from 0 to 21 and means and standard deviations were estimated. The higher scores reflect higher levels of knowledge about cervical cancer prevention.

\section{Second tool:}

The Health Belief Model was adopted from [21, 22, 23], modified and translated into Arabic language by the researchers. The HBM sub constructs which used in this study were perceived susceptibility (5 items) perceived severity (4 items) to cervical cancer, perceived barriers of performing Pap smear and HPV vaccination (10 items), and perceived benefits of Pap smear and HPV vaccination (5 items).

\section{Scoring system of Health Belief Model:}

The questionnaire included 24 items on a 5-point Likert scale ranging from 1 (strongly disagree) to 5 (strongly agree). Subscale mean scores were obtained by summing and averaging the items (range 1-5). Each subscale was calculated separately, and therefore four different scores were obtained for each subject. The total score ranged 24-120, and a higher score point out a more positive belief toward cervical cancer prevention behaviors with the exception of perceived barriers of Pap smear and receiving HPV vaccine.

\section{Third tool:}

Questionnaire to assess intention to practice cervical cancer prevention behaviors (pre/post test format) which encompassing (2) questions: the first, doing a Pap smear test, and the second, receiving HPV vaccination.

\section{Scoring system of intent to practice cervical cancer prevention behaviors:}

For each question, the responses were coded each intent to practice cervical cancer behaviors was scored "one", and each no intent was scored "zero". The total intention score was measured by summation the scores for the possess intention responses. 


\section{Tools validity and reliability:}

The tools and the package were reviewed for comprehensiveness, appropriateness, and legibility by an expert panel consisting of five obstetrics and woman health nursing as well as community health nursing experts. The panel ascertained the face and content validity of the tools. The reliability was done by Cronbach's Alpha coefficient test which revealed that each of the three tools consisted of relatively homogenous items as indicated by the moderate to high reliability of each tool. The internal symmetry of knowledge was 0.91; the total HBM was 0.81 , with breakdowns by category: 0.72 (perceived susceptibility to the disease), 0.83 (perceived severity of the disease), 0.86 (perceived benefits of Pap smear and HPV vaccination), 0.78 (perceived barriers of performing Pap smear and receiving HPV vaccine), and intention to practice cervical cancer prevention behaviors was 0.79 .

\section{Ethical considerations:}

Each student in both groups was informed about the purpose and benefits of the study then oral consent was obtained before starting the data collection. Strict confidentiality was ensured throughout the study process. The students were assured that all data was used only for research purpose and each student was informed of the rights to refuse or withdraw at any time with no consequences. After the study was completed, the self learning package was distributed to control group.

\section{Pilot study:}

Pilot study was conducted on $10 \%$ of studied sample (31 students) to assess the clarity, objectivity and feasibility of the tools. As well to estimate the time needed for data collection. Those students in the pilot study were not included in the main study sample since some modifications were done.

\section{Field work:}

The researchers obtained a written letter from the Dean of the Faculty of Nursing, Benha University and hand over to the Secretary General of Benha University to get the statistical numbers of female students enrolled within each faculty of the university. Another written official letter was taken and delivered to the dean of each faculty, in order to obtain their approval for conduction of the research after explaining its purpose. At the time of data collection a verbal agreement was taken from every participant in the study after clear and proper explanation of the study purpose and its importance for them.

The study was carried out through four phases: assessment, planning, implementation, and evaluation. These phases were carried out from beginning of October 2013 to the end of April 2014, covering along a period of seven months. The previous mentioned settings were visited by the researchers two days/week (Monday and Wednesday) from 10.00 am to $2.00 \mathrm{pm}$.

\section{Assessment phase:}

Upon securing official permissions to conduct the study, the researchers approached and interviewed each student individually in both control and intervention groups, explained the purpose and procedures of the study, and asked for her participation. After obtaining oral consent to participate in the study, the student received the self-administered questionnaire to assess students' general characteristics and knowledge regarding cervical cancer prevention, health belief model, and questionnaire to assess intention to practice cervical cancer prevention behaviors and asked to fill it. The information obtained during this phase formed the baseline for further comparisons to estimate the effect of self learning package. To avoid cross contamination of information between both groups, control group was assessed first. Average time for the completion of each student interview was around (30-45 minutes). A number of interviewed students / week ranged from 16-18 students.

\section{Planning and implementation phase:}

According to the needs which be identified in the assessment phase and in review of the related literature [24, 25], the researchers developed learning package about cervical cancer prevention based on HBM constructs with simple Arabic language to suit students' level of understanding, which aimed to improve female University students' knowledge, modify their health beliefs, and empower them to take health decisions for cervical cancer preventive behaviors. It clarified the areas of common deficiency in students' knowledge related to cervical cancer prevention, health beliefs and intention to practice cervical cancer preventive behaviors as meaning of cervical cancer, causes, risk factors, signs and symptoms, diagnosis, methods of treatment and prevention, cervical cancer screening, time, purposes, benefits and technique of Pap smear, and HPV vaccination (benefits, safety, and availability, recommended age for vaccination, who should receive the HPV vaccination). Self learning package distributed to each student in intervention group. The researchers explained to the students how to use the package throughout setting directions including;

1. Carefully read each chapter, and avoid cancel any page in the package. 
2. The questions after each chapter should be answered.

3. Students can go to the model key answer after finishing the reading carefully.

4. Students can return to the researchers in order to clarify the vague points and answer any questions via email, telephone numbers and meeting the students in their faculties.

\section{Evaluation phase:}

The effect of the self-learning package based on health belief model was estimated after two months of handed the self-learning package to the intervention group, by using the same format of pre-test, first of all post-test was done for control group then intervention group.

\section{Statistical analysis:}

Data were verified prior to computerized entry. The Statistical Package for Social Sciences (SPSS version 20.0) was used for that purpose, followed by data analysis and tabulation. Descriptive statistics were applied (e.g., mean, standard deviation, frequency and percentages).Test of significance (chi-square and independent $t$ test) were used to test the homogeneity of the outcome variables between the groups and to test the study hypothesis. Pearson correlation coefficients were used. A statistically significant difference was considered at $p$-value $p \leq 0.05$, and a highly a statistically significant difference was considered at $p$-value $\mathrm{p} \leq 0.001$.

\section{Results}

Table (1) shows socio demographic characteristics of the studied sample. It was clear that more than half $(51.0 \%$ and $54.8 \%)$ of both intervention and control groups respectively were in age group $21<23$ years with a mean age of $20.97 \pm 0.98$ years and $20.95 \pm 1.04$ years respectively. As regards the faculty type, $61.8 \%$ of the intervention group and $59.2 \%$ of control group were enrolled in literary faculties. Furthermore, more than half of two groups were enrolled in the fourth year. As far as monthly income, less than three quarters of the intervention and control groups (73.9\% and $71.3 \%$ respectively) had insufficient income. No statistically difference was detected among both groups related to socio demographic characteristics, which mean that the two groups under study are homogenous.

Table (2) illustrates that, $56.1 \%$ of intervention and $59.9 \%$ of control groups were married at age less than or equal twenty years old with mean age at marriage was $20.49 \pm 0.65$ and $20.41 \pm 0.53$ years of both intervention and control groups respectively. The mean of marriage duration for both intervention and control groups was $(7.11 \pm 5.54$ and $7.63 \pm 4.87$ months respectively). About two thirds of both intervention and control groups were nullipara (63.7\% and $66.9 \%$ respectively). Additionally, $28.6 \%$ of intervention group as well as $21.4 \%$ of control group use contraceptive methods, from them (71.4\%) of the intervention group and (78.6\%) of control group used contraceptive pills. As observed from this table no statistically significant difference between intervention and control groups related to marital status and obstetric history.

Fig. (1) reveals that a $7.6 \%$ and $8.9 \%$ of the intervention and control groups respectively have a family history of cervical cancer.

Table (3) indicates that, no statistically significant difference was found between both intervention and control groups before self-learning package implementation related to cervical cancer knowledge, cervical cancer screening, Pap smear and HPV vaccination. Meanwhile, a highly statistically significant difference was found after two months of implementing self-learning package observed between two groups at p-values < 0.001 .

Table (4) clarifies that, the health beliefs mean scores in the both groups were the same in all items with no statistically significant difference was found. However, after two months of implementing self-learning package, the mean scores of perceived susceptibility, severity, and benefits of early detection and HPV vaccination were significantly higher in the intervention group compared with control group. Also findings confirmed that the perceived barriers mean scores of early detection and HPV vaccination were statistically significantly reduced in intervention group rather than the control group.

Fig. (2) displays that, no one of two groups have intent to receive HPV vaccination and Pap smear before self learning package implementation. Meanwhile, after self-learning package implementation, 38.2\% and $53.5 \%$ of the intervention group have intent to receive HPV vaccination and Pap smear respectively compared with $3.2 \%$ and $5.7 \%$ of the control respectively.

Table (5) demonstrates that, a highly statistically significant positive correlation was found among total knowledge and total health beliefs scores in both studied groups before and after self-learning package implementation. Moreover, a highly statistically significant positive correlation was detected between total 
knowledge and total intention scores in two groups before and after two months of implementing self-learning package.

Table (6) indicates that, a highly significant positive correlation was discovered between total health beliefs score and total intention score in two groups after two months of self learning package implementation.

Table (1) Distribution of the studied sample according to their socio-demographic characteristics $(n=314)$.

\begin{tabular}{|c|c|c|c|c|c|c|}
\hline \multirow{2}{*}{$\begin{array}{l}\text { Group } \\
\text { Socio demographic } \\
\text { characteristics }\end{array}$} & \multicolumn{2}{|c|}{$\begin{array}{l}\text { Intervention group } \\
\mathrm{n}=157\end{array}$} & \multicolumn{2}{|c|}{$\begin{array}{l}\text { Control group } \\
\mathrm{n}=157\end{array}$} & \multirow[t]{2}{*}{$\mathbf{X}^{2}$} & \multirow[t]{2}{*}{ p value } \\
\hline & No & $\%$ & No & $\%$ & & \\
\hline \multicolumn{7}{|l|}{ Age ( years) } \\
\hline $19-$ & 54 & 34.4 & 52 & 33.1 & & \\
\hline $21-$ & 80 & 51.0 & 86 & 54.8 & 0.540 & 0.763 \\
\hline$\geq 23$ & 23 & 14.6 & 19 & 12.1 & & \\
\hline Mean \pm SD & \multicolumn{2}{|c|}{$20.97 \pm 0.98$} & \multicolumn{2}{|c|}{$20.95 \pm 1.04$} & & \\
\hline \multicolumn{7}{|l|}{ Type of Faculty } \\
\hline Scientific & 60 & 38.2 & 64 & 40.8 & 0.213 & 0.644 \\
\hline Literary & 97 & 61.8 & 93 & 59.2 & & \\
\hline \multicolumn{5}{|l|}{ Academic year } & \multirow{3}{*}{0.462} & \multirow{3}{*}{0.497} \\
\hline Third year & 69 & 43.9 & 75 & 47.8 & & \\
\hline Fourth year & 88 & 56.1 & 82 & 52.2 & & \\
\hline \multicolumn{5}{|l|}{ Monthly income } & \multirow{3}{*}{0.256} & \multirow{3}{*}{0.613} \\
\hline Sufficient & 41 & 26.1 & 45 & 28.7 & & \\
\hline Insufficient & 116 & 73.9 & 112 & 71.3 & & \\
\hline
\end{tabular}

Table (2) Distribution of the studied sample according to their marital and obstetric history $(\mathrm{n}=314)$.

\begin{tabular}{|c|c|c|c|c|c|c|}
\hline \multirow{2}{*}{$\begin{array}{c}\text { Group } \\
\begin{array}{c}\text { Marital and obstetric } \\
\text { history }\end{array} \\
\end{array}$} & \multicolumn{2}{|c|}{$\begin{array}{l}\text { Intervention group } \\
\mathrm{n}=157\end{array}$} & \multicolumn{2}{|c|}{$\begin{array}{l}\text { Control group } \\
\mathrm{n}=157\end{array}$} & \multirow[t]{2}{*}{$\mathbf{X}^{2}$} & \multirow[t]{2}{*}{$p$ value } \\
\hline & No & $\%$ & No & $\%$ & & \\
\hline \multicolumn{7}{|l|}{ Age at marriage ( years) } \\
\hline$\leq 20$ & 88 & 56.1 & 94 & 59.9 & 0.471 & 0.493 \\
\hline$>20$ & 69 & 43.9 & 63 & 40.1 & & \\
\hline Mean \pm SD & \multicolumn{2}{|c|}{$20.49 \pm 0.65$} & \multicolumn{2}{|c|}{$20.41 \pm 0.53$} & & \\
\hline \multicolumn{7}{|c|}{ Duration of marriage (months) } \\
\hline Mean \pm SD & \multicolumn{2}{|c|}{$7.11 \pm 5.54$} & \multicolumn{2}{|c|}{$7.63 \pm 4.87$} & & \\
\hline \multicolumn{5}{|l|}{ Parity } & \multirow{4}{*}{1.270} & \multirow{4}{*}{0.530} \\
\hline Nullipara & 100 & 63.7 & 105 & 66.9 & & \\
\hline One & 56 & 35.7 & 52 & 33.1 & & \\
\hline Two & 1 & 0.6 & 0 & 0.0 & & \\
\hline \multicolumn{7}{|c|}{ Use of contraceptive methods } \\
\hline Yes & 49 & 31.2 & 42 & 26.8 & 0.758 & 0.384 \\
\hline \multicolumn{7}{|c|}{ Kinds of contraceptive methods } \\
\hline Pills & 35 & 71.4 & 33 & 78.6 & 0.611 & 0.434 \\
\hline IUD & 14 & 28.6 & 9 & 21.4 & & \\
\hline
\end{tabular}

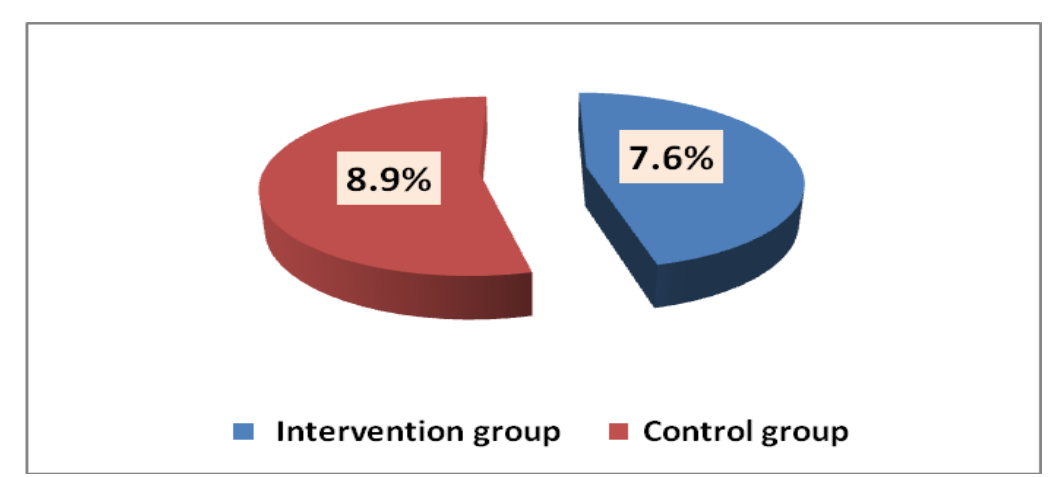

Fig. (1) Distribution of the studied sample according to their family history of cervical cancer $(n=314)$. 
Effect of Self Learning Package Based on Health Belief Model on Cervical Cancer Prevention...

Table (3) Mean scores of the studied sample knowledge regarding cervical cancer prevention in the intervention and control groups before and after two months of self learning package implementation $(\mathbf{n}=\mathbf{3 1 4})$

\begin{tabular}{|c|c|c|c|c|c|c|c|c|c|}
\hline \multirow{3}{*}{$\begin{array}{l}\text { Knowledge } \\
\text { items }\end{array}$} & \multirow{3}{*}{$\begin{array}{l}\text { Maximum } \\
\text { score }\end{array}$} & \multicolumn{4}{|c|}{ Before SLP implementation } & \multicolumn{4}{|c|}{$\begin{array}{l}\text { After two months of SLP } \\
\text { implementation }\end{array}$} \\
\hline & & $\begin{array}{l}\text { Intervention } \\
\text { group } \\
\mathrm{n}=157\end{array}$ & $\begin{array}{l}\text { Control group } \\
\mathbf{n}=\mathbf{1 5 7}\end{array}$ & test & p value & $\begin{array}{l}\text { Intervention } \\
\text { group } \\
\mathrm{n}=157\end{array}$ & $\begin{array}{l}\text { Control } \\
\text { group } \\
\mathbf{n = 1 5 7}\end{array}$ & test & p value \\
\hline & & Mean \pm SD & Mean \pm SD & & & Mean \pm SD & Mean \pm SD & & \\
\hline Cervical cancer & 7 & $1.65 \pm 1.36$ & $1.51 \pm 1.39$ & 0.902 & 0.368 & $6.40 \pm 0.84$ & $1.61 \pm 1.23$ & 39.452 & $0.000 * *$ \\
\hline $\begin{array}{lr}\text { Cervical } & \text { cancer } \\
\text { screening } & \text { and } \\
\text { Pap smear } & \end{array}$ & 9 & $1.19 \pm 0.86$ & $1.12 \pm 0.98$ & 0.671 & 0.503 & $7.86 \pm 0.95$ & $1.22 \pm 1.56$ & 45.532 & $0.000 * *$ \\
\hline $\begin{array}{l}\text { HPV } \\
\text { vaccination }\end{array}$ & 5 & $0.05 \pm 0.22$ & $0.03 \pm 0.16$ & 1.176 & 0.240 & $4.37 \pm 0.83$ & $0.04 \pm 0.21$ & 63.598 & $0.000^{* *}$ \\
\hline Total & 21 & $2.89 \pm 1.86$ & $2.65 \pm 1.54$ & 1.220 & 0.224 & $18.64 \pm 1.93$ & $2.88 \pm 1.55$ & 79.969 & $0.000 * *$ \\
\hline
\end{tabular}

The test used independent $t$ test between intervention and control group.

**A highly statistical significant difference $(P \leq 0.001)$

Table (4) Mean scores of constructs of Health Belief Model in the intervention and control groups before and after two months of self learning package implementation $(n=314)$

\begin{tabular}{|c|c|c|c|c|c|c|}
\hline \multirow{3}{*}{ Health Belief Model constructs } & \multicolumn{3}{|c|}{ Before SLP implementation } & \multicolumn{3}{|c|}{$\begin{array}{l}\text { After two months of } \\
\text { implementation }\end{array}$} \\
\hline & \multirow{2}{*}{$\begin{array}{l}\text { Intervention } \\
\text { group } \\
\text { n=157 } \\
\text { Mean } \pm \text { SD } \\
\end{array}$} & \multirow{2}{*}{$\begin{array}{l}\begin{array}{l}\text { Control } \\
\text { group } \\
\text { n=157 }\end{array} \\
\text { Mean } \pm \text { SD } \\
\end{array}$} & \multirow[t]{2}{*}{$\begin{array}{l}\text { p } \\
\text { value }\end{array}$} & $\begin{array}{l}\text { Intervention } \\
\text { group } \\
\mathbf{n = 1 5 7}\end{array}$ & $\begin{array}{l}\text { Control } \\
\text { group } \\
\mathbf{n}=\mathbf{1 5 7}\end{array}$ & \multirow[t]{2}{*}{ p value } \\
\hline & & & & Mean \pm SD & Mean \pm SD & \\
\hline \multicolumn{7}{|l|}{ Perceived susceptibility } \\
\hline I am at risk for developing cervical cancer. & $1.64 \pm 0.77$ & $1.54 \pm 0.73$ & 0.461 & $2.20 \pm 1.08$ & $1.59 \pm 0.72$ & $0.000 * *$ \\
\hline $\begin{array}{l}\text { My chances of getting cervical cancer in the next } \\
\text { few years are high. }\end{array}$ & $2.86 \pm 1.13$ & $2.94 \pm 1.32$ & 0.700 & $3.86 \pm 1.58$ & $2.99 \pm 1.27$ & $0.000 * *$ \\
\hline $\begin{array}{l}\text { There is a good possibility that I will get cervical } \\
\text { cancer }\end{array}$ & $3.65 \pm 1.13$ & $3.70 \pm 1.28$ & 0.793 & $4.91 \pm 0.28$ & $3.75 \pm 1.06$ & $0.000 * *$ \\
\hline $\begin{array}{l}\text { If I do not have symptoms, I do not need a Pap } \\
\text { screening. }\end{array}$ & $3.73 \pm 1.26$ & $3.83 \pm 1.33$ & 0.626 & $2.63 \pm 1.69$ & $3.89 \pm 1.35$ & $0.000 * *$ \\
\hline $\begin{array}{l}\text { My family history puts me at risk for getting } \\
\text { cervical cancer. }\end{array}$ & $2.85 \pm 0.59$ & $2.74 \pm 1.05$ & 0.407 & $4.95 \pm 0.27$ & $2.76 \pm 0.96$ & $0.000 * *$ \\
\hline Total score $=25$ & $14.71 \pm 2.22$ & $14.84 \pm 3.00$ & 0.765 & $18.55 \pm 1.49$ & $15.20 \pm 2.88$ & $0.000 * *$ \\
\hline \multicolumn{7}{|l|}{ Perceived severity } \\
\hline Cervical cancer may lead to death. & $3.40 \pm 1.06$ & $3.66 \pm 1.12$ & 0.131 & $4.78 \pm 0.45$ & $3.71 \pm 1.13$ & $0.000 * *$ \\
\hline Cervical cancer may lead to a hysterectomy. & $3.78 \pm 1.27$ & $3.58 \pm 1.23$ & 0.314 & $4.91 \pm 0.33$ & $3.60 \pm 1.52$ & $0.000 * *$ \\
\hline Cervical cancer is a serious health problem. & $3.69 \pm 0.99$ & $3.62 \pm 1.04$ & 0.640 & $4.79 \pm 0.44$ & $3.85 \pm 1.08$ & $0.000 * *$ \\
\hline $\begin{array}{l}\text { Cervical cancer can lead to a female needing to } \\
\text { receive chemotherapy or radiotherapy treatment. }\end{array}$ & $3.64 \pm 1.14$ & $3.59 \pm 1.12$ & 0.780 & $4.79 \pm .49$ & $3.70 \pm 1.09$ & $0.000 * *$ \\
\hline Total score $=\mathbf{2 0}$ & $14.50 \pm 3.64$ & $14.41 \pm 2.98$ & 0.868 & $19.26 \pm 1.03$ & $14.85 \pm 3.29$ & $0.000 * *$ \\
\hline \multicolumn{7}{|l|}{ Perceived barriers } \\
\hline Getting cervical test would only make me worry. & $4.14 \pm 1.18$ & $4.24 \pm 1.12$ & 0.582 & $2.64 \pm 0.82$ & $4.14 \pm 1.18$ & $0.000 * *$ \\
\hline $\begin{array}{l}\text { Screening is not necessary since there is no cure for } \\
\text { cancer. }\end{array}$ & $3.73 \pm 1.23$ & $3.83 \pm 1.21$ & 0.605 & $1.81 \pm 1.04$ & $3.73 \pm 1.22$ & $0.000 * *$ \\
\hline The Pap screening is painful. & $3.94 \pm 1.14$ & $4.04 \pm 1.09$ & 0.572 & $2.14 \pm 1.13$ & $3.95 \pm 1.15$ & $0.000 * *$ \\
\hline $\begin{array}{l}\text { It is too expensive to have a Pap screening or HPV } \\
\text { vaccination. }\end{array}$ & $4.00 \pm 1.28$ & $4.08 \pm 1.23$ & 0.706 & $3.05 \pm 0.93$ & $4.01 \pm 1.29$ & $0.000 * *$ \\
\hline It is too embarrassing to have a Pap screening. & $4.09 \pm 2.64$ & $4.10 \pm 1.16$ & 0.947 & $2.64 \pm 1.53$ & $4.09 \pm 1.17$ & $0.000 * *$ \\
\hline $\begin{array}{l}\text { I haven't taken the Pap test because I am afraid to } \\
\text { find out if I have cancer. }\end{array}$ & $4.36 \pm 1.03$ & $4.41 \pm 1.02$ & 0.758 & $2.33 \pm 1.37$ & $4.40 \pm 0.98$ & $0.000 * *$ \\
\hline $\begin{array}{l}\text { I don't know where I could go if I wanted to do a } \\
\text { Pap screening. }\end{array}$ & $4.56 \pm 0.94$ & $4.58 \pm 0.92$ & 0.933 & $2.60 \pm 1.33$ & $4.51 \pm 0.94$ & $0.000 * *$ \\
\hline $\begin{array}{l}\text { I do not know at what age it is necessary to have } \\
\text { a screening test. }\end{array}$ & $4.39 \pm 0.99$ & $4.36 \pm 1.01$ & 0.875 & $2.88 \pm 1.49$ & $4.34 \pm 0.99$ & $0.000 * *$ \\
\hline $\begin{array}{l}\text { I do not know how often I need to get a Pap } \\
\text { screening. }\end{array}$ & $4.44 \pm 0.71$ & $4.41 \pm 0.72$ & 0.826 & $2.55 \pm 1.55$ & $4.45 \pm 0.61$ & $0.000 * *$ \\
\hline $\begin{array}{l}\text { I think getting the HPV vaccination series might be } \\
\text { unsafe or harmful to my health }\end{array}$ & $4.40 \pm 0.98$ & $4.49 \pm 0.99$ & 0.575 & $2.75 \pm 1.51$ & $4.46 \pm 0.95$ & $0.000 * *$ \\
\hline Total score $=\mathbf{5 0}$ & $42.04 \pm 7.75$ & $42.52 \pm 7.62$ & 0.689 & $25.38 \pm 5.79$ & $42.08 \pm 7.64$ & $0.000 * *$ \\
\hline \multicolumn{7}{|l|}{ Perceived benefits } \\
\hline $\begin{array}{l}\text { A Pap screening can find cervical changes before } \\
\text { they become cancer. }\end{array}$ & $1.35 \pm 0.71$ & $1.34 \pm 0.69$ & 0.911 & $4.48 \pm 0.86$ & $1.35 \pm 0.71$ & $0.000 * *$ \\
\hline If cervical changes are found early they are easily & $1.63 \pm 1.05$ & $1.53 \pm 1.07$ & 0.551 & $4.79 \pm 0.44$ & $1.54 \pm 1.08$ & $0.000 * *$ \\
\hline
\end{tabular}


Effect of Self Learning Package Based on Health Belief Model on Cervical Cancer Prevention...

\begin{tabular}{|l|l|l|l|l|l|l|}
\hline curable. & & & & & \\
\hline $\begin{array}{l}\text { It is important for a female to have a Pap screening } \\
\text { so she will know if she is healthy. }\end{array}$ & $1.71 \pm 0.89$ & $1.70 \pm 0.92$ & 0.930 & $4.18 \pm 1.11$ & $1.79 \pm 0.87$ & $0.000^{* *}$ \\
\hline The Pap screening can save my life. & $1.49 \pm 0.81$ & $1.48 \pm 0.84$ & 0.924 & $4.35 \pm 0.99$ & $1.49 \pm 0.84$ & $0.000^{* * *}$ \\
\hline $\begin{array}{l}\text { The innovative HPV vaccine is an effective primary } \\
\text { prevention strategy for cervical cancer. }\end{array}$ & $1.88 \pm 0.97$ & $1.89 \pm 0.99$ & 0.936 & $4.21 \pm 0.96$ & $1.90 \pm 0.99$ & $0.000^{* *}$ \\
\hline Total score $=\mathbf{2 5}$ & $\mathbf{8 . 1 3} \pm \mathbf{2 . 4 6}$ & $\mathbf{8 . 0 1} \pm 2.35$ & $\mathbf{0 . 7 6 8}$ & $\mathbf{2 2 . 0 0} \pm \mathbf{3 . 4 1}$ & $\mathbf{8 . 1 5} \pm \mathbf{2 . 8 9}$ & $\mathbf{0 . 0 0 0} * *$ \\
\hline Total score $=\mathbf{1 2 0}$ & $\mathbf{7 9 . 4 1} \pm \mathbf{1 0 . 0 7}$ & $\mathbf{7 9 . 7 4} \pm 11.03$ & $\mathbf{0 . 8 4 6}$ & $\mathbf{8 5 . 1 5} \pm \mathbf{6 . 8 9}$ & $\mathbf{8 0 . 5 7} \pm \mathbf{1 1 . 6 1}$ & $\mathbf{0 . 0 0 3} * *$ \\
\hline
\end{tabular}

The test used independent $t$ test between intervention and control group.

**A highly statistical significant difference $(\mathrm{P} \leq \mathbf{0 . 0 0 1})$

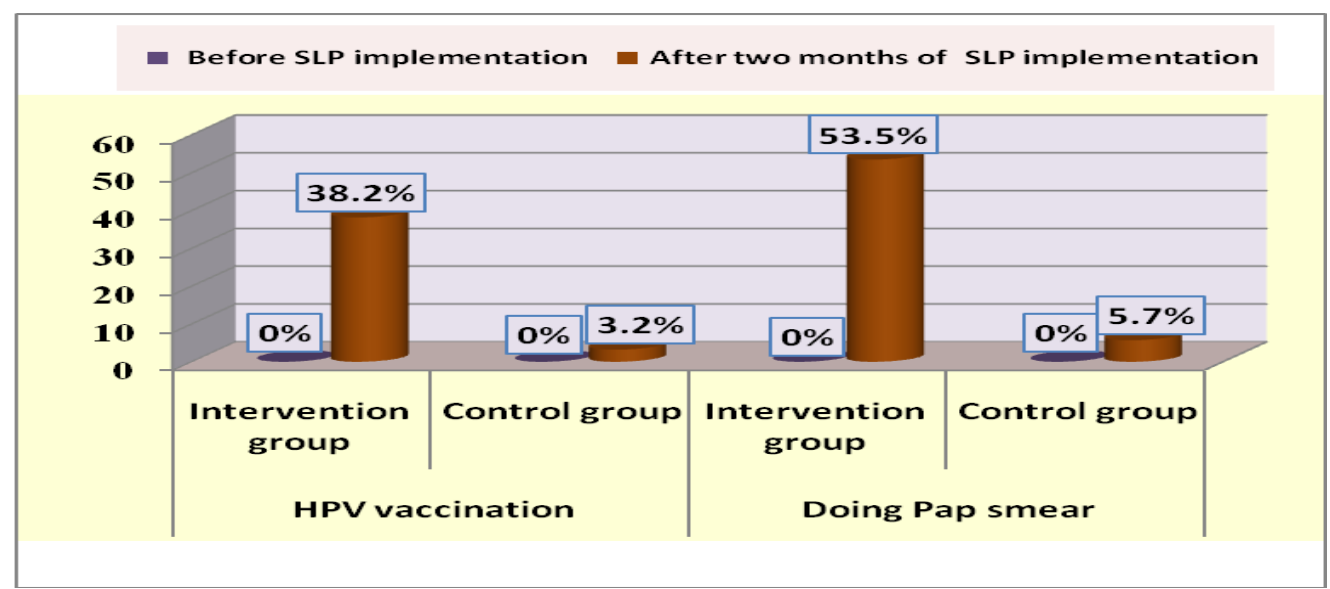

Fig. (2) Distribution of the studied sample according to their intention to practice prevention behaviors of cervical cancer before and after self learning package implementation $(n=314)$.

Table (5) Correlation coefficient between total scores of knowledge, health beliefs and intention regarding cervical cancer prevention of the studied sample before and after two months self learning package implementation $(\mathbf{n}=314)$.

\begin{tabular}{|c|c|c|c|c|c|}
\hline \multirow{3}{*}{\multicolumn{2}{|c|}{ Variables }} & \multicolumn{4}{|c|}{ Total knowledge score } \\
\hline & & \multicolumn{2}{|c|}{$\begin{array}{l}\text { Intervention group } \\
\mathrm{n}=157\end{array}$} & \multicolumn{2}{|c|}{$\begin{array}{l}\text { Control group } \\
\mathbf{n}=157\end{array}$} \\
\hline & & $\mathbf{r}$ & $\mathbf{p}$ & $\mathbf{r}$ & $\mathbf{p}$ \\
\hline \multirow{2}{*}{$\begin{array}{l}\text { Total health beliefs } \\
\text { score }\end{array}$} & Before of SLP impleme & 0.647 & $0.000^{* *}$ & 0.620 & $0.000^{* * *}$ \\
\hline & After two months of SLP implementation & 0.839 & $0.000 * *$ & 0.665 & $0.000 * *$ \\
\hline \multirow{2}{*}{$\begin{array}{l}\text { Total intention } \\
\text { score }\end{array}$} & Before of SLP implementation & 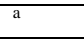 & - & 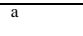 & - \\
\hline & After two months of SLP implementation & 0.606 & $0.000^{* * *}$ & 0.215 & $0.007^{* * *}$ \\
\hline
\end{tabular}

**Correlation is highly significant at $(\mathbf{P} \leq \mathbf{0 . 0 1})$

${ }^{a}$ Cannot be computed because at least one of the variables is constant.

Table (6) Correlation coefficient between total heath beliefs and intention scores regarding cervical cancer prevention of the studied sample before and two months after self learning package implementation $(\mathbf{n}=314)$.

\begin{tabular}{|c|c|c|c|c|c|}
\hline \multirow{3}{*}{\multicolumn{2}{|c|}{ Variables }} & \multicolumn{4}{|c|}{ Total health beliefs score } \\
\hline & & \multicolumn{2}{|c|}{$\begin{array}{l}\text { Intervention group } \\
\mathrm{n}=157\end{array}$} & \multicolumn{2}{|c|}{$\begin{array}{l}\text { Control group } \\
\mathbf{n}=157\end{array}$} \\
\hline & & $\mathbf{r}$ & $\mathbf{p}$ & $\mathbf{r}$ & $\mathbf{p}$ \\
\hline \multirow{2}{*}{$\begin{array}{l}\text { Total intention } \\
\text { score }\end{array}$} & Before of SLP implementation & $\mathrm{a}$ & - & $\mathrm{a}$ & - \\
\hline & $\begin{array}{l}\begin{array}{l}\text { After two months of } \\
\text { implementation }\end{array}\end{array}$ & 0.522 & $0.000^{* * *}$ & 0.310 & $0.007 * *$ \\
\hline
\end{tabular}

**Correlation is highly significant at $(\mathbf{P} \leq \mathbf{0 . 0 1})$

${ }^{a}$ Cannot be computed because at least one of the variables is constant.

\section{Discussion}

Cervical cancer is a critical burden on the reproductive health of women globally, in spite of the fact that it is preventable and a main fact of its prevention is early detection of the precancerous form by cervical screening. Additionally, it is one kind of cancer which can be prevented and cured if discovered early [26].

The current study results revealed that more than half of both intervention and control groups were in age group $21<23$ years with a mean age of $20.97 \pm 0.98$ and $20.95 \pm 1.04$ years respectively. This result is in 
agreement with Mohamed [27] who found that the mean age of the studied students was $20.1 \pm 0.5$ years, $74.3 \%$ of them ranged between 20-21 years. Also this finding supports by Hoque [28] who found that the mean age of the participants was 20.81 1.7 years. According to Huebner [29] who emphasized that this age is considered as risk factor of infection, and infection complications. This finding is supported with cervical cancer prevention guidelines from the American Cancer Society [30] which highlighted that cervical cancer screening should begin at age 21 , and regular screenings are even more critical for sexually active women.

Less than two thirds of both groups enrolled in literary faculties. In addition, more than half of the intervention and control groups were in the fourth year, less than three quarters of the studied and control groups didn't have sufficient monthly income. These findings are in agreement with Mohamed [27] this study showed that, there was no a statistically significant difference between intervention and control groups regarding socio demographic characteristics. This may mean that the studied intervention and control groups are similar. These findings are in accordance with Suk, et al., [31] who revealed that there were no statistically significant differences between the studied groups regarding their characteristics.

According the present study, result showed that more than half of intervention and control groups were married at age less than or equal twenty years old of both intervention and control groups respectively. This finding is slightly higher than the study of assessment of the knowledge and attitude of female students towards cervical cancer prevention at an international university in Japan done by Ghotbi and Anai [32] which revealed that the age when the greatest number of students had their first sex experience was 18years. This may be due to different culture between the Egypt and Japan.

Moreover, less than three quarters of the intervention group and more than three quarters of control group used contraceptive pills from total number of students who use contraceptive methods (28.6\% of intervention group as well as $21.4 \%$ of control group use contraceptive methods respectively). This may be due to the mean duration of their married years was short and they want to have a child. A few of the intervention and control groups have family history of cervical cancer. This finding agrees with Juntasopeepun et al., [33] who found that there was $9.6 \%$ family history of cervical cancer among young women in Thailand.

On investigating cervical cancer prevention knowledge of studied samples related to cervical cancer prevention, the findings of this study indicated that, no statistically difference was found among both intervention and control groups before implementation of self learning package regarding knowledge about cervical cancer, cervical cancer screening, and Pap smear and HPV vaccination. Meanwhile, rising in the mean scores of all items regarding cervical cancer prevention knowledge was observed with a highly significant improvement after two months of self learning package implementation observed between two groups. These may be due to the female university students' ability to gain knowledge easily, they are interested in the research topics and the effectiveness of the SLP. These findings are matched with Pirzadeh and Mazaheri [34] who found that the knowledge mean score before the intervention in two groups was poor while after educational intervention, the level of knowledge mean score improved significantly that is emphasized on the effect of the education on knowledge.

After self-learning package implementation, a significant improvement in all HBM constructs perceived susceptibility, severity, benefits of early detection and HBV vaccination and barriers of early detection and HPV vaccination. This improvement denoted to positive health beliefs regarding cervical cancer prevention. These are supported by Shojaeizadeh et al., [17] who found that education based on HBM was effective and could improve the HBM constructs including perceived susceptibility, severity, benefits, and barriers. In addition, Suk, et al., [31] found that a peer education program developed to promote cervical cancer preventive behaviors for female college students had positively changes of attitudes toward cervical cancer prevention behaviors.

The mean scores of cervical cancer perceived susceptibility in the both groups were low. This is in the same line with Wilson [35] who reported that college students do not perceive themselves to be at high risk for HPV or other sexual transmitted diseases. However, after implementing self learning package, the mean scores of perceived susceptibility increased in the intervention group, as well as there was a slightly increase in the mean scores of perceived susceptibility in control group. This significant improvement may be indicated that self-learning package based on Health Belief Model affect on female university students behaviors in which they recognized that they could contract cervical cancer, but slightly increasing in perceived susceptibility of control group explained by the fact that all participants in this study were university students who some of them became interested to gain facts data about cervical cancer from different sources as internet after met the researchers. This is congruent with Pirzadeh and Mazaheri [34]) who found that the mean score of perceived susceptibility increased in the intervention group following the intervention.

The mean scores of perceived severity in the both groups were low before implementing self-learning package. This finding is contrast with Holguin [36] who documented that when asked about the seriousness of getting cervical cancer, slightly over $90 \%$ of women strongly agreed that getting cervical cancer is a serious health issue. However, the mean scores of perceived severity increased in intervention group after self learning 
package based on Health Belief Model implementation with highly statistically significant difference observed between both groups.

Additionally, the results also confirmed that before self learning package implementation, the mean scores of perceived barriers of performing Pap smear and HPV vaccination in the both groups were high. This may be due to the fact that lack of knowledge about Pap smear and HPV vaccination as well as study sample did not know where the test is done and had sense of shame to do Pap smear or take sexual transmitted diseases vaccine. This is supported by Reis et al., [37] who emphasized that the women had negative Pap smear barriers; these barriers consisted of fear, anxiety. On the other hand, after self learning package based on Health Belief Model implementation the mean scores of perceived barriers of performing Pap smear and HPV vaccination were significantly decreased in intervention group but not in the control group. In this respect Suk et al., [31] who stated that the hindrance to preventive behaviors of cervical cancer post program had statistically significant improvement between the two groups and the barriers to HPV vaccination comprise the rising vaccine cost, and worry of adverse effects of vaccine.

In relation to perceived benefits of Pap smear and HPV vaccination, the results of the current study revealed that, the mean scores of perceived benefits of Pap smear and HPV vaccination in the both groups were low. On the other hand, intervention group perceived benefits mean scores improved after implementing selflearning package with highly statistically significant improvement noticed among both groups. This is consistent with Fouda and Elhossiny [38] who found that there was a significant improvement post intervention in perceived benefits of cervical cancer early detection and vaccination among the studied women.

Moreover, the intervention and control groups have no intention to receive the vaccine of HPV and perform Pap smear before implementation of self-learning package. This may be attributed to the absence of designed educational program provided to these students about Pap smear and HPV vaccination. Also the cancer screening services are yet inadequate in Egypt and to the absence of screening culture in Egyptian culture. However, after two months of self learning package implementation, more than half and more than one third of the intervention group has intent to do Pap smear and to receive HPV vaccination respectively. This may due to the effect of the self learning package based on health belief model in helping the female university students in decision making regarding their health, and in having a positive health behaviors, However, some of participants did not decide to do the test or vaccine, this may be attributed to many factors such as religious factors and costs of these services. This is supported by Ibrahim [39] who stressed those religious factors where Muslims and Arabic women believe in fatalism and socio-economic factors whereas the coverage of cancer screening services is still limited in Egypt. In addition, Perrin et al., [40] who highlighted that, social, cultural, religious and ethical issues can create difficulties when administering a vaccine that prevents a sexually transmitted infection to young women.

The results of the current study indicated that, there was a positive highly statistically significant correlation between total knowledge and total health beliefs scores in both intervention and control groups before and after two months of self learning package implementation. Moreover, there was a positive highly statistically significant correlation between total knowledge and total intention scores in both groups before and after two months of self learning package implementation. This may be due to self learning package provided the participants with valuable information that can affect their health beliefs which in turn increase intention to use preventive behaviors. These findings are in congruence with Kang and Kim [9] who stressed that increased knowledge was associated with improved cervical cancer prevention behaviors, and the intent to practice cervical cancer preventive behaviors

There was a positive highly statistically significant correlation between total health beliefs score and total intention score in both intervention and control groups after two months of self learning package implementation. This may be due to intention to receive an HPV vaccination and do Pap smear linked with perceived participants' benefits of these preventive behaviors. In addition, individual's health beliefs regarding cervical malignant tumors and its screening may have a main role as a hindrance to females' compliance with screening practices. This is similar with Juntasopeepun et al., [33] who reported that beliefs play a vital role in a person's decision to engage in health preventive behaviors. HPV vaccine acceptability has been shown to be influenced by beliefs about disease and vaccination.

\section{Conclusion}

Based on the results of the present study, the self learning package based on HBM enhanced the married female students ' knowledge regarding cervical cancer prevention, significantly change positively health beliefs and intention to practice cervical cancer prevention behaviors such as doing Pap test and receiving HPV vaccination. These study findings were supported the study hypotheses. 


\section{Recommendations}

Based on the findings of the current study, the following recommendations can be suggested:

- Dissemination of cervical self learning package based on HBM among female university students to prevent the risk of cervical cancer.

- Periodic examination of the university student's health beliefs is crucial in any intervention program planning.

- HPV vaccination should be recommended before marriage for female.

- Further researches: replication of the research on a large probability sample is recommended to achieve more generalization.

[1]. World Health Organization (2011): Cancer fact sheet, available at: http://www.who.int/mediacentre/ factsheets/fs297/en/index.html

[2]. Ombech, E., Muigai, A., and Wanzala, P., (2012): Awareness of cervical cancer risk factors and practice of Pap smear testing among female primary school teachers in Kasarani division, Nairobi Kenya, African Journal of Health Sciences, 21(2): 121132.

[3]. Urasa, M., and Darj, E., (2011): Knowledge of cervical cancer and screening practices of nurses in Tanzania. African Health Sciences, 11: 48-57.

[4]. Schuiling, K., and Likis, F., (2011): Women's gynecologic health, $2^{\text {nd }}$ ed., Jones and Bartlett, USA., p 708.

[5]. National Cancer Institute, (2011): available at: http://www.cancer.gov/cancertopics/types/cervical.

[6]. Centers for Disease Control and Prevention, (2013): Sexually transmitted diseases: Genital HPV infection-Fact sheet. Retrieved from http://www.cdc.gov/hpv/whatishpv.html.

[7]. McFarland, D., (2009): Beliefs about the causes of cervical cancer in Botswana: implications for nursing. Int. Nursing Review, 56(1):426-32.

[8]. Al-Naggar, R., Low, W., and Isa, Z., (2010): Knowledge and barriers towards cervical cancer screening among young women in Malaysia, Asian Pacific J Cancer Prev, 11, 867-873.

[9]. Kang, H., and Kim, J., (2011): Knowledge, attitudes of human Papillomavirus vaccine, and intention to obtain vaccine among Korean female undergraduate students, Women \&Health, 51 (8): 759-776.

[10]. Sequeira,A., (2012): Self learning is the Future: A new Paradigm for the $21^{\text {st }}$ Century, National Institution of Technology Karnataka, Surathkal, Available at: http://Papers.ssrn.com /so13.

[11]. Glanz, K., Rimer, B., and Viswanath, K., (2008): Health behavior and health education: Theory, research, and practice, $4^{\text {th }}$ ed., San Francisco, John Wiley and Sons, pp45- 66.

[12]. Hajializadeh K., Ahadi, H., Jomehri, F., and Rahgozar, M.,(2013): Health beliefs and screening behavior of cervical cancer among the females of Bandar Abbas, Life Science Journal, 10(1): 545-551.

[13]. Mali, N., and Mali, R., (2014): Effect of structured education on knowledge regarding prevention among A.N.M. students, International Journal of Science and Research, 3 (3): 2319-7064.

[14]. Phianmongkhol, Y., Suwan, N., Srisomboon, J., and Kietpeerakool, C., (2011): Knowledge about Human Papillomavirus infection and cervical cancer prevention among nurses in Chiang Mai University Hospital, Thailand, Asian Pacific J Cancer Prev., 12(1): $823-825$.

[15]. Naik, P., Nagaraj, K., and Nirgude, A., ( 2012): Awareness of cervical cancer and effectiveness

of educational intervention programme among nursing students in a rural area of Andhra Pradesh, health line, 3 (2): p41.

[16]. ICO Information Centre on HPV and Cancer, (2014): Human Papillomavirus and Related Cancers, Fact Sheet 2013, Available at: .www.hpvcentre.net/statistics/reports/EGY_FS.pdf.

[17]. Shojaeizadeh, D., Hashemi, S., Moeini, B., and Poorolajal, J., (2011): The effect of educational program on increasing cervical cancer screening behavior among women in Hamadan, Iran: Applying Health Belief Model, Journal of Research in Health Sciences, $11(1): 20-25$.

[18]. Yamane, T., (1967): Statistics: An Introductory Analysis, $2^{\text {nd }}$ ed., New York, Harper and Row, p 886.

[19]. Hoque, M., (2010): Cervical Cancer Awareness and Preventive Behavior among Female University Students in South Africa, Asian Pacific Journal of Cancer Prevention, 11(10): 127-130.

[20]. Marek. E., Timea. D., Gabor, A., Istvan. S., Istvan , K., Gocze, P., and D’Cruz, G., (2012): Effect

of an educational intervention on Hungarian adolescents' awareness, beliefs and attitudes on the prevention of cervical cancer, Vaccine 30 (1): 6824 6832 .

[21]. Lee, E., and Park, J., (2011): Knowledge about cervical cancer, health beliefs and human Papillomavirus vaccination rate in female university students. Journal of Korean Oncology Nursing, 11 (1), 65-73.

[22]. Duran, E., (2011): Examination with the health belief model of females' attitude to cervical cancer and early diagnosis in Turkey: Qualitative study. Asian Pacific Journal of Cancer Prevention, 12(5): 1179-1184.

[23]. Han, K., (2011): The impact of health belief components on the effectiveness of women's cancer prevention campaigns: A crossnational examination towards Korean and Japanese women. Korean Journal of Advertizing and Public Relations, 13 (2): $377-412$.

[24]. Parks, B., (2010): Compared effectiveness of two health education teaching methods on human Papillomavirus knowledge and beliefs among students ages 18-24 at a Historically Black University, Master Thesis, Faculty of the Graduate School, Howard University, pp48-62.

[25]. Ndikom, C., and Ofi, B., (2011): Pre-screening counseling in cervical cancer prevention: Implications for nursing, International Journal of Nursing and Midwifery, 3(10):158-164.

[26]. Isa, I., Gani, O., and McFubara, K., (2013): Cervical cancer screening among female undergraduates and staff in the Niger delta region of Nigeria, Open Journal of Obstetrics and Gynecology, 3(1): 61-66.

[27]. Mohamed, H., (2013): Health practices among female university students regarding prevention of reproductive tract infections, Master thesis, Faculty of nursing, Benha University, p61.

[28]. Hoque, M., (2013): Awareness of cervical cancer, Papanicolau's smear and its utilization among female, final year undergraduates in Durban, South Africa Journal of Cancer Research and Therapeutics, $\quad 9$ (1): 25-28.

[29]. Huebner, A., (2006): Adolescent Growth and Development. Available at: www.ext.vt.edu/pubs/family/ 350-850/350-850.html. 
[30]. American Cancer Society, (2012): New screening guidelines for cervical cancer. Retrieved from http://www.cancer.org/ cancer/news/new-screening-guidelines-for-cervical-cancer.

[31]. Suk, M., Bong, C., and Sun, K., (2013): Effects of a peer cervical cancer prevention education program on Korean female college students' knowledge, attitude, self-efficacy, and intention, Korean J Adult Nurs., 25 (6): 736-746.

[32]. Ghotbi, N., and Anai, A., (2012): Assessment of the knowledge and attitude of female students towards cervical cancer prevention at an international university in Japan, Asian Pacifc Journal of Cancer Prevention,13(1): 897-900.

[33]. Juntasopeepun, P., Davidson, P., Suwan, N., Phianmongkhol, Y., Srisomboon, J., (2012): Human Papillomavirus vaccination intention among young women in Thailand, Asian Pacific J Cancer Prev, 13(1):3213-3219.

[34]. Pirzadeh, A., and Mazaheri, M., (2012): The effect of education on women's practice based on the health belief model about Pap Smear Test, Int J Prev Med., 3(8): 585-590.

[35]. Wilson, T., (2010):The Relationship Between Knowledge and Beliefs About Human Papillomavirus, Acceptance of the Human Papillomavirus Vaccine, and intentions to practice safer sex behaviors among female college students, Doctor thesis, College of Public Health, University of South Florida, pp1-5.

[36]. Holguin, A., (2009): Determining the knowledge and attitudes of 18- to 26-year-old women regarding cervical cancer, human Papillomavirus, and the human Papillomavirus vaccine, Master thesis, Health, Physical Education and Recreatio, Utah State University, pp 27-30.

[37]. Reis, N., Bebis, H., Kose, S., Sis, A., Engin, R., and Yavan,T.,(2012): Knowledge, behavior and beliefs related to cervical cancer and screening among Turkish females. Asian Pacific J Cancer Prev, 13, 1463-1470.

[38]. Fouda, L., and Elhossiny, E., (2013): The impact of an educational intervention on women's knowledge and perception regarding cervical cancer and human Papillomavirus vaccines in Tanta City: Applying Health Belief Model, Life Science Journal,10 (12s):997-1005.

[39]. Ibrahim, H., (2011): Effect of an educational program about breast and cervical cancer on knowledge, attitude and practices of working women in Benha University, Doctorate Thesis, Faculty of Nursing, Benha University, p107.

[40]. Perrin, K., Thaker, R., Daley, E., Vamos, C., and Patel, P., (2013): HPV knowledge and behavioral intention among health science undergraduate students: Influence of future health care professionals, NHL Journal of medical sciences, 2(2):15-21. 